\title{
Role of curcumin in mesenteric ischemia - reperfusion injury in rats
}

\author{
Nurullahoglu-Atalik $\mathrm{KE}^{1}$, Okudan $\mathrm{N}^{2}$, Belviranli $\mathrm{M}^{2}$, Gokbel $\mathrm{H}^{2}, \mathrm{Oz} \mathrm{M}^{2}$, Esen $\mathrm{H}^{3}$ \\ Department Pharmacology, Meram Faculty of Medicine, Selcuk University, Konya, Turkey. \\ esraatalik@hotmail.com
}

\begin{abstract}
Background: Curcumin is an antioxidant molecule that has been shown to attenuate ischemia/reperfusion (I/R) injury in several organ systems. In the present study, we aimed to evaluate the possible effects of curcumin on contractile response to agonists and histopathological alterations in rat esophagus subjected to mesenteric I/R.

Materials and methods: Adult male Wistar albino rats were randomly allocated to 4 groups, namely group I: sham-operated animals $(n=10)$; group II: animals subdued to I/R injury only $(n=10)$ and laparotomy; 45 minutes of superior mesenteric artery ligation were followed by 2 hours of reperfusion, group III: curcumin/sham $(n=10)$; 20 days before I/R, curcumin $(200 \mathrm{mg} / \mathrm{kg} /)$ was administered by gastric gavage, and group IV: curcumin-I/R $(n=10)$. Mesenteric ischemia/reperfusion model was generated by clamping the superior mesenteric artery for $45 \mathrm{~min}$ followed by reperfusion for $2 \mathrm{~h}$. Oral administration of curcumin by gavage at a dose of $200 \mathrm{mg} / \mathrm{kg} / \mathrm{day}$ lasted 20 days just before inducing the mesenteric ischemia. At the end of reperfusion period, all animals were sacrificed and esophagus samples were collected to assess the contractile response to agonists and histopathological alterations.

Results: Ischemia/reperfusion significantly decreased the contractile responses to carbachol and $\mathrm{KCl}$ and this decrease was attenuated by curcumin. Pretreatment with curcumin caused a remarkable decrease in histopathological parameters such as edema, congestion and inflammatory cells.

Conclusions: The results of the present study demonstrate for the first time that curcumin can attenuate the esophageal injury associated with I/R (Tab. 4, Fig. 3, Ref. 32). Full Text in PDF www.elis.sk.

Key words: contractile function, curcumin, esophagus, mesenteric ischemia.
\end{abstract}

Mesenteric ischemia is frequently encountered in multiple disease states and surgical procedures including cardiovascular interventions, small bowel transplantation mesenteric thrombosis, shock syndromes, and severe burns $(1,2)$. The ensuing reperfusion is unavoidable and may induce downstream tissue injury. Intestinal ischemia and reperfusion injury can accelerate interactions between endothelium and different cell types resulting in microvascular injury, cellular necrosis, and apoptosis (3-6). During mesenteric ischemia/reperfusion (I/R), reactive oxygen species (ROS) attack the cell membrane constituents and thus bring about lipid peroxidation, membrane disintegration, and increased microvascular permeability. The latter induces activation and adhesion of polymorphonuclear neutrophils (PMNs), release of proinflammatory substances, and increased formation of ROS. Activated neutrophils in this tissue enhance ROS and cytotoxic protein production, which leads to an induction of inflammatory cascade $(3,4)$ resulting in cell death and organ failure. The inten-

${ }^{1}$ Department Pharmacology, Meram Faculty of Medicine, Selcuk University, Konya, Turkey, ${ }^{2}$ Department of Physiology, Meram Faculty of Medicine, Selcuk University, Konya, Turkey, and ${ }^{3}$ Department of Pathology, Meram Faculty of Medicine, Selcuk University, Konya, Turkey

Address for correspondence: K. Esra Nurullahoglu-Atalik, Department of Pharmacology, Faculty of Meram Medicine, University of Selcuk, Konya, 42080, Turkey.

Fax: +90.332 .2237124$ sity of this inflammatory reaction in postischemic tissue can be so great that the injury response to reperfusion is manifested also in distant organs. These remote effects of I/R are most frequently observed in the lung and cardiovascular system, and can possibly result in the development of systemic inflammatory response syndrome (SIRS) and multiple organ dysfunction syndrome (MODS) (7). To counter these processes, various therapeutic strategies have been attempted to attenuate the mesenteric $\mathrm{I} / \mathrm{R}$ injury including antileukocyte and anti inflammatory therapies, as well as glutamine, glycine and antioxidant supplementation $(5,8)$.

Curcumin (diferuloyl methane) is a polyphenolic diketone found in Curcuma longa Linn. (Family Zingiberaceae). The rhizomes of the plant are a rich source of phenolic compounds, particularly curcumin. It possesses extensive pharmacological and therapeutic properties, including anticarcinogenic effects, and exhibits a potent antioxidant property (9-12). Curcumin is known to be a potent inhibitor of nuclear factor- $\kappa \mathrm{B}(\mathrm{NF}-\mathrm{\kappa B})$. It has been shown to attenuate I/R injury in several organ systems. Recently, it has been reported that curcumin administration ameliorated I/R injury in rat kidney, myocardium, and nervous tissue (13). Curcumin treatment has been recently shown to attenuate reperfusion injury in a superior mesenteric artery I/R model in rats (14).

Despite numerous studies on the effects of I//R on the mesenteric smooth muscle responses, its probable effect on esophageal smooth muscle responses has not been delineated. Therefore, the 
present study was designed to investigate the effects of $\mathrm{I} / \mathrm{R}$ on rat esophageal responses and the role of curcumin supplementation.

\section{Materials and methods}

\section{Chemicals}

Carbachol was purchased from Sigma (Sigma Chemical Co., St. Louis, MO, USA) and dissolved in double distilled water. Compounds used for preparing the Tyrode's solution, were purchased from Merck (Merck KGaA, Darmstadt, Germany).

\section{Animals}

In this study, 40 male Wistar-Albino rats weighing between 280 and 300 gr were used. Animals were kept under standardized conditions; $20 \pm 2{ }^{\circ} \mathrm{C}, 50 \pm 5 \%$ humidity, 12/12 light-dark cycles at Selçuk University Experimental Medicine Research and Application Center. The rats were fed a standard laboratory diet with water ad libitum. The local ethics committee of our institution approved this study. The animals were randomly divided into four groups; ten animals in each groups. Sham: animals exposed to laparotomy without clamping the superior mesenteric artery (SMA); I/R (ischemiareperfusion): animals exposed to laparotomy with occlusion of SMA for $45 \mathrm{~min}$, followed by $120 \mathrm{~min}$ of reperfusion period; Curcumin/ Sham: $200 \mathrm{mg} / \mathrm{kg}$ of curcumin as described before (15-17) was given with oral gavage for 20 days to animals who were thereafter exposed to laparotomy without clamping the SMA; Curcumin/I/R: $200 \mathrm{mg} / \mathrm{kg}$ of curcumin was given with oral gavage for 20 days to animals who were thereafter exposed to laparotomy with occlusion of SMA for $45 \mathrm{~min}$, followed by $120 \mathrm{~min}$ of reperfusion period.

\section{Ischemia-reperfusion protocol}

Animals were anesthetized by intraperitoneal injection of ketamin hydrochloride plus xylazin. The abdomen was opened with a midline incision. The intestinal I/R injury was established by occluding the SMA with atraumatic microvascular clip for 45 min followed by $120 \mathrm{~min}$ reperfusion. Ischemia was recognized by absence of pulse or pale color of intestine. Following ischemia, the microvascular clamp was removed and reperfusion was confirmed by restoration of pulsation and color prior to closing the incision. Sham-operated animals were submitted to the abdominal incision without I/R.

\section{Curcumin supplementation}

Curcumin (Curcuma longa; Turmeric) was purchased from Sigma Aldrich (C1386). Curcumin dissolved in corn oil (Sigma C8257). Rats in Curcumin/Sham and Curcumin/IR groups were given $200 \mathrm{mg} / \mathrm{kg}$ of curcumin with oral gavage for 20 days.

\section{Preparation of esophagus}

The rats were harvested by decapitation and almost $1.5 \mathrm{~cm}$ of thoracic portion of esophagus was excised. Esophageal smooth muscle strips were prepared and mounted in $20 \mathrm{ml}$ organ chambers for isometric tension measurement. The organ chambers contained Tyrode's solution composed of ( $\left.\mathrm{mmol} \mathrm{l}^{-1}\right)$ : $\mathrm{NaCl} 136.0 ; \mathrm{KCl} 2.7$; $\mathrm{CaCl}_{2} 1.8 ; \mathrm{MgCl}_{2} 1.05 ; \mathrm{NaH}_{2} \mathrm{PO}_{4} \cdot \mathrm{H}_{2} \mathrm{O} 0.42 ; \mathrm{NaHCO}_{3} 11.9$; glucose
5.5. The solution was gassed with $95 \% \mathrm{O}_{2}$ and $5 \% \mathrm{CO}_{2}$ during the study, and the temperature was maintained at $37{ }^{\circ} \mathrm{C}$. The strips were connected to a force transducer (BIOPAC MP36, Santa Barbara, California, USA) connected through amplifiers to a ITBS08 Integrated Tissue Bath System (Commat, Ankara, Turkey). The strips were allowed to equilibrate for 90 min under a resting tension of $0.5 \mathrm{~g}$ before the experiments began. During this period the bath fluid was routinely changed every $15 \mathrm{~min}$.

\section{Esophageal contractility}

At the end of the equilibration period, carbachol $\left(10^{-9}-3 \times 10^{-4} \mathrm{M}\right)$ was added in a cumulative manner to the organ baths.

In another part of the study the same procedure was applied with cumulative addition $(5-100 \mathrm{mM})$ of $\mathrm{KCl}$ to the organ baths. Each experiment was performed with a tissue sample taken from one animal.

\section{Histopathologic examination}

Immediately after death, the tissues in a $10 \%$ formaldehyde solution were processed in a cassette autotechnic tissue-processing equipment (Leica ASP 300). When the processing was completed, the tissues were embedded in paraffin blocks and sections ( $5 \mu \mathrm{m}$ in thickness) taken by microtome instrument onto lysine laminin. The preparations stained with hematoxylin and eosin were evaluated by Olympus BX51 microscope.

The histopathological evaluation of tissue damage included the intensity of inflammatory cell infiltration, edema, congestion, hemorrhage erosion, muscular degeneration, necrosis and fibrosis. Each parameter was scored between 0 and 3 (0: normal, 1: mild, 2: moderate and 3: severe).

\section{Biochemical Analysis}

Interleukin-6 (IL-6) and tumor necrosis factor- $\alpha$ (TNF- $\alpha$ ) levels were analyzed in serum samples by using commercially available kits (BenderMed System, Vienna, Austria) according to manufacturer's instructions. Myeloperoxidase (MPO) activity was analyzed in intestinal tissue to determine ischemia by using a commercially available kit (Hycult Biotechnology, Uden, The Netherlands) according to manufacturer's instructions. The protein content of tissues was determined by the method of Lowry et al (18).

\section{Statistical analysis}

Concentrations of contractile agents causing $50 \%$ of the maximal response $\left(\mathrm{EC}_{50}\right)$ were calculated from each individual concentration-response curve. The maximum effect values were calculated as a percentage of maximum response of tissue to carbachol and potassium chloride. Maximal responses and $\mathrm{EC}_{50}$ values for curves obtained from each groups were compared by using the unpaired or paired Student's t test, as appropriate. The difference was assumed to be significant at $\mathrm{p}<0.05$.

The histopathological results were expressed as median (minmax). All numerical data were first analyzed using the nonparametric Kruskal-Wallis test (whether there was a difference between groups) and then the Mann-Whitney U-test was performed to analyze two groups consecutively. 


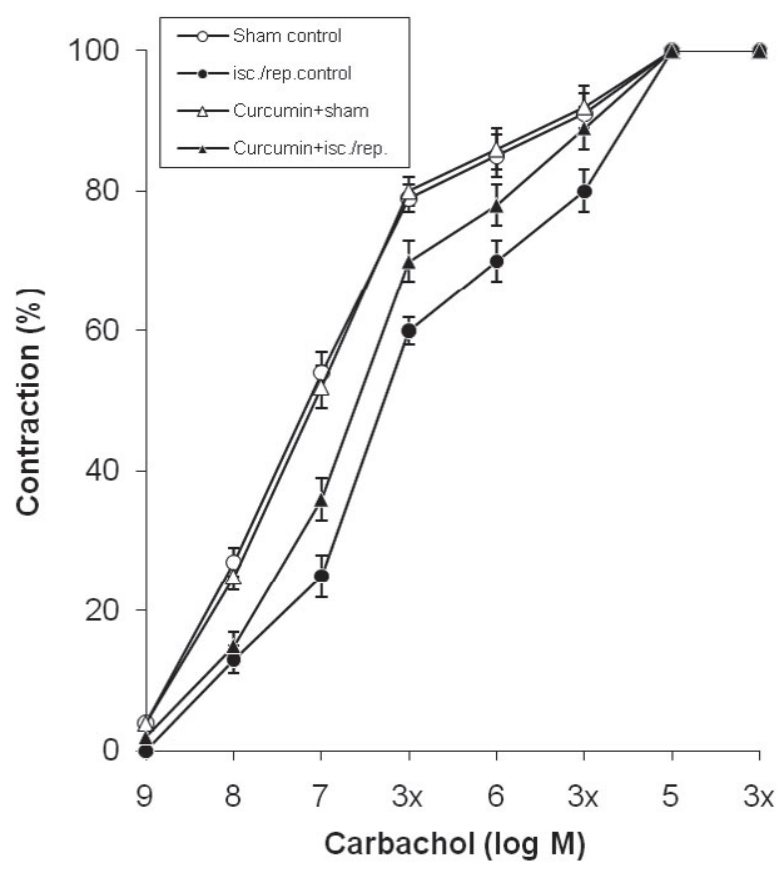

Fig. 1. Carbachol concentration-response curves of esophagus from sham control rats, $I / R$ control rats, curcumin-treated rats and curcumin-treated I/R rats. Each point is the mean \pm SEM of six experiments.

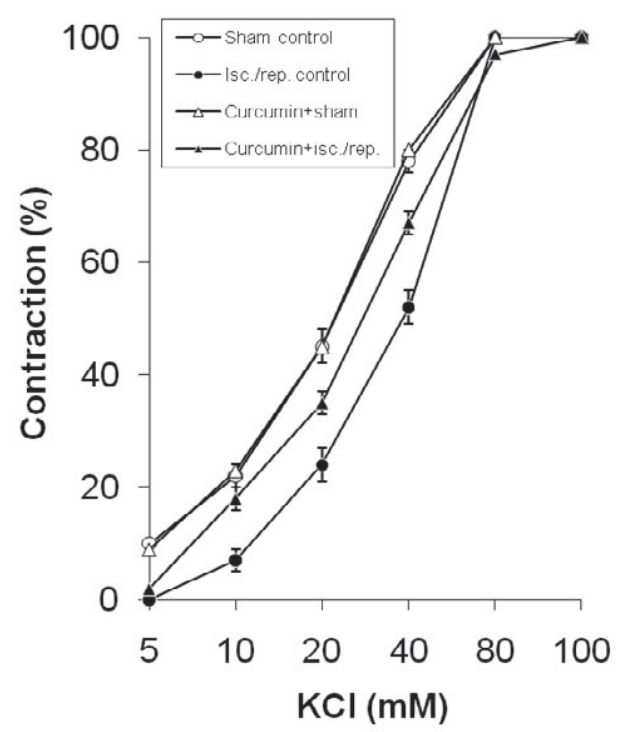

Fig. 2. KCl concentration-response curves of esophagus from sham control rats, I/R control rats, curcumin-treated rats and curcumintreated $\mathrm{I} / \mathrm{R}$ rats. Each point is the mean \pm SEM of six experiments.

\section{Results}

\section{Esophagus contractility}

The addition of carbachol at concentration from $10^{-9} \mathrm{M}$ to $3 \times 10^{-4} \mathrm{M}$ into organ bath fluid resulted in a dose-dependent contractile effect on the esophageal strips from all groups, providing
Tab. 1. EC50 values for carbachol and $\mathrm{KCl}$ of esophagus from rats. Each value is derived from six experiments. Data are means \pm SEM.

\begin{tabular}{lcc}
\hline & Carbachol $\left(\times 10^{-7} \mathrm{M}\right)$ & $\mathrm{KCl}\left(\times 10^{-2} \mathrm{M}\right)$ \\
\hline Sham control & $7.0 \pm 0.1$ & $2.3 \pm 0.1$ \\
Isc./rep. & $2.2 \pm 0.1^{\mathrm{a}}$ & $3.8 \pm 0.1^{\mathrm{a}}$ \\
Curcumin & $8.6 \pm 0.2^{\mathrm{b}}$ & $2.2 \pm 0.2^{\mathrm{b}}$ \\
Curcumin + isc./rep. & $1.6 \pm 0.2^{\mathrm{b}}$ & $2.8 \pm 0.1^{\mathrm{b}}$ \\
\hline${ }^{\mathrm{a}} \mathrm{p}<0.05$ compared to Sham control, ${ }^{\mathrm{b}} \mathrm{p}<0.05$ compared to Isc./rep.
\end{tabular}

Tab. 2. $\mathrm{E}_{\max }$ (g) values for carbachol and $\mathrm{KCl}$ of esophagus from rats. Each value is derived from six experiments. Data are means \pm SEM.

\begin{tabular}{lcc}
\hline & Carbachol & $\mathrm{KCl}$ \\
\hline Sham control & $4.5 \pm 0.1$ & $3.0 \pm 0.1$ \\
Isc./rep. & $2.9 \pm 0.1 \mathrm{a}$ & $1.6 \pm 0.1 \mathrm{a}$ \\
Curcumin & $4.9 \pm 0.2 \mathrm{~b}$ & $3.3 \pm 0.2 \mathrm{~b}$ \\
Curcumin+isc./rep. & $5.3 \pm 0.2 \mathrm{~b}$ & $4.3 \pm 0.1 \mathrm{~b}$ \\
\hline${ }^{\mathrm{a}} \mathrm{p}<0.05$ compared to Sham control, ${ }^{\mathrm{b}} \mathrm{p}<0.05$ compared to Isc./rep.
\end{tabular}

sigmoid curves (Fig. 1). The dose-response curve obtained from tissues of animals subjected to I/R without administrating anything shifted to the right. In other words, the contractile responses induced by carbachol were significantly and dose-dependently inhibited by the induction of IR $(\mathrm{p}<0.05)$. $\mathrm{E}_{\max }$ value for carbachol in the I/R control group was significantly lower than in the sham-operated control group (Tab. 1). The IR-induced reduction in contractility was significantly ameliorated by pretreatment with curcumin. Treatment of sham animals with curcumin has provided the same contractile response curve with similar $\mathrm{E}_{\max }$ value as sham alone group does.

In response to cumulative concentrations of $\mathrm{KCl}$ ranging from $2 \mathrm{mM}$ to $10 \mathrm{mM}$, esophagus strips contracted in a dose-dependent fashion in all groups, rendering sigmoid curves with $\mathrm{EC}_{50}$ and $\mathrm{E}_{\text {max }}$ values (Fig. 2). The contractile response induced by $\mathrm{KCl}$ was significantly and dose-dependently inhibited by the induction of I/R. Reduced contractility due to I/R was significantly ameliorated by curcumin pretreatment. Pretreating sham animals with curcumin caused similar dose-response curve to sham-operated group in respect of $\mathrm{EC}_{50}$ and $\mathrm{E}_{\max }$ values.

\section{Histopathological findings}

Based on histopathological analysis of 6 sections for each group, the most extensive changes in morphology were evident in I/R control group (Fig. 3). Edema, congestion, and inflammatory cell infiltration were clearly observed and noticed as grades 2 and 3. In sham-operated control group, no pathological change was detected as demonstrated in picture A; grading as 0 . The analysis also showed that the pretreatment with curcumin restored remarkably the typical alterations in morphology as depicted in Table 2. Sections obtained from curcumin-pretreated sham group were observed with normal morphological appearance, identical to those from sham-operated control group (Tab. 3).

\section{Biochemical findings}

Serum IL- 6 and TNF- $\alpha$ levels were not different among the groups. Intestinal MPO activity was lower in Curcumin/Sham group compared to that in IR group $(\mathrm{p}<0.05)$ (Tab. 4). 

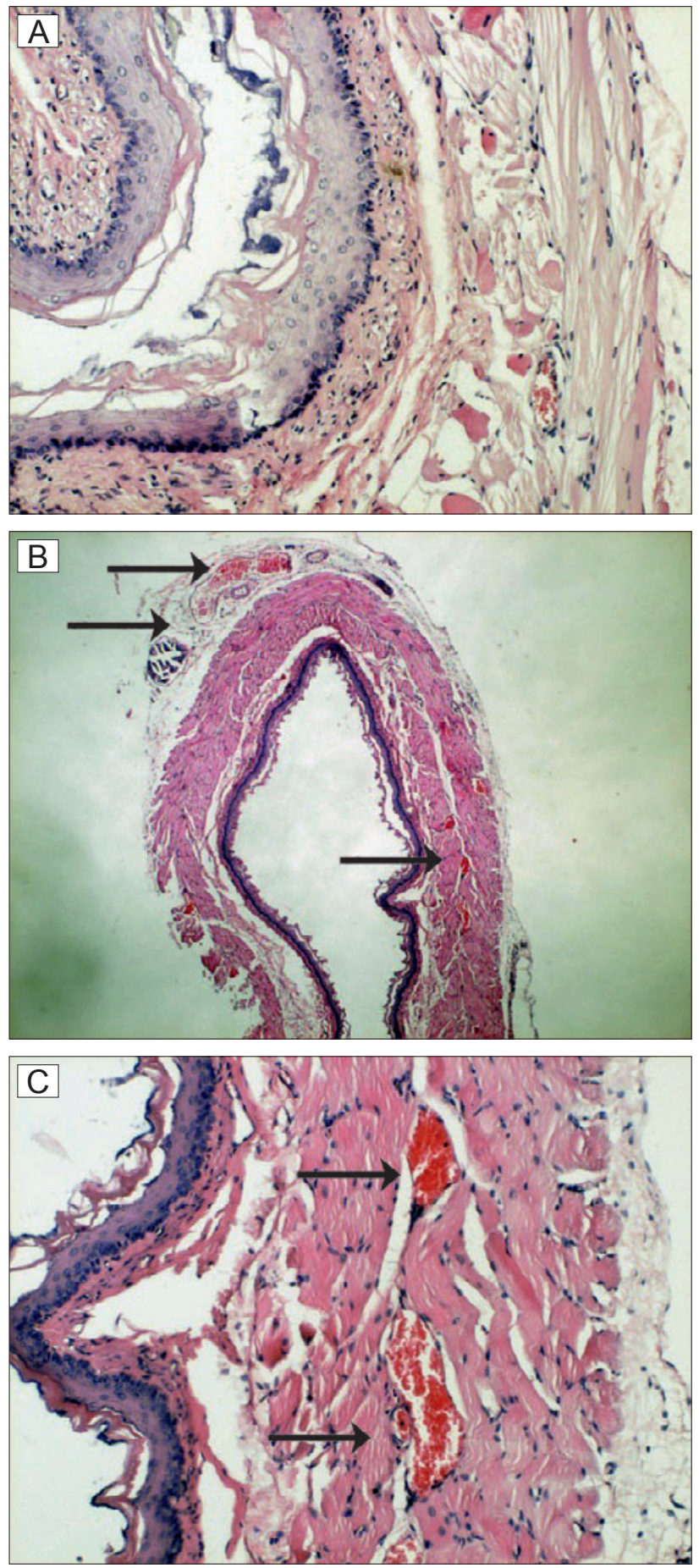

\section{Discussion}

The present study demonstrated that mesenteric I/R resulted in a decreased esophageal contractility in response to both carbachol, receptor-mediated induction, and $\mathrm{KCl}$, non-receptor-mediated induction. Decreased contractile response observed also in non-receptor-mediated induction supports the possibility that
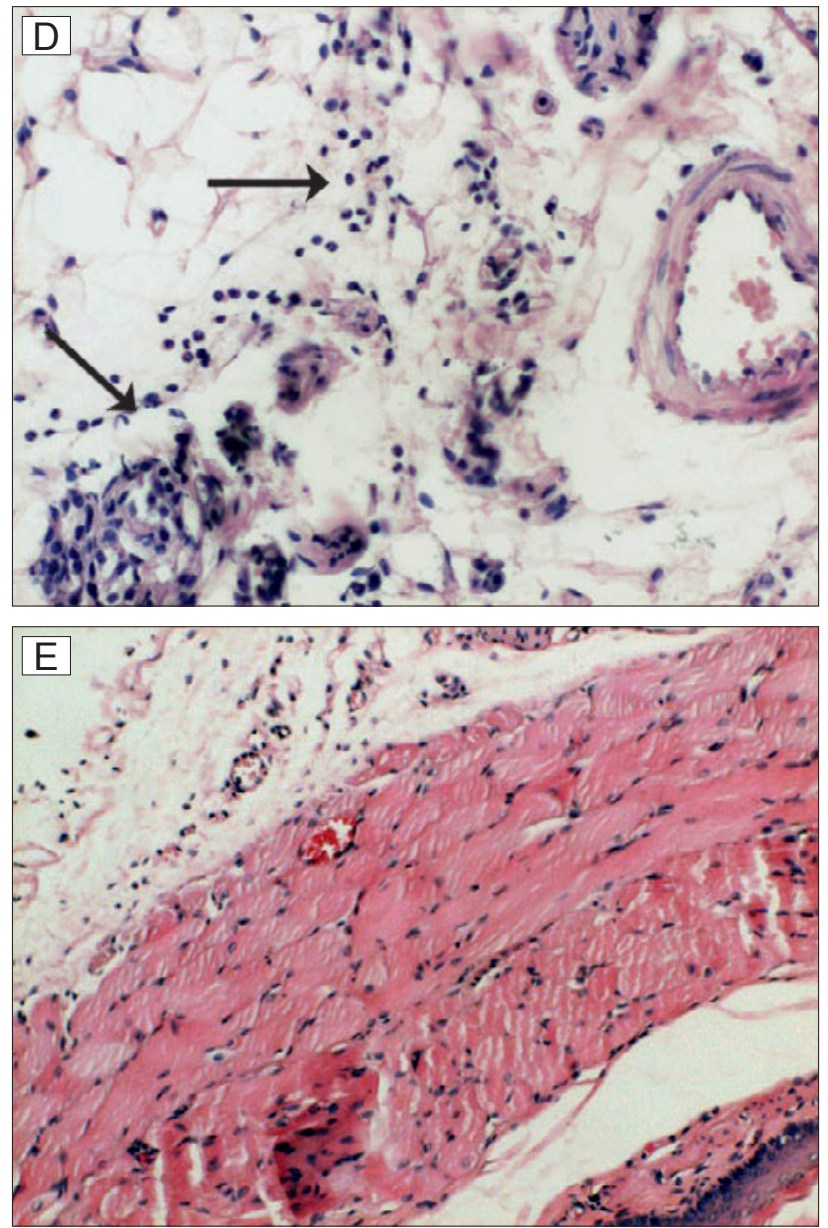

Fig. 3. Typical histological features in IR group and the control group. Light micrographs of rat esophagus tissue: (A) Sham operated control group; normal architecture (grade 0); (B,C,D) ischemia/reperfusion group; the most extensive morphological changes detected; edema (grade 2), congestion (grade 3) and inflammatory cells (grade 2.5); (E) Curcumin+isc./rep.; less congestion (grade 2) and inflammatory cells (grade 1.5). (H\&E A,D, E: X100, B: X20, C: X200).

ischemia/reperfusion may not alter the ligand-receptor interaction but rather changes the regulation of postreceptor processes (i.e. excitation-contraction coupling) (19). Our data are consistent with these findings. This study also reveals that curcumin pretreatment prevents the esophageal dysfunction and demonstrates a protective effect against esophageal damage resulting from mesenteric ischemia-reperfusion. This is the first report to show that curcumin 
Tab. 3. Comparison of histological damage of rat esophagus median (min-max).

\begin{tabular}{|c|c|c|c|c|c|c|c|c|}
\hline & Edema & Congestion & $\begin{array}{c}\text { Inflammatory } \\
\text { cells }\end{array}$ & Haemorrhage & Erosion & Necrosis & Fibrosis & $\begin{array}{c}\text { Muscular } \\
\text { degeneration }\end{array}$ \\
\hline Control & $0(0-0)$ & $0(0-0)$ & $0(0-0)$ & $0(0-0)$ & $0(0-0)$ & $0(0-0)$ & $0(0-0)$ & $0(0-0)$ \\
\hline $\mathrm{I} / \mathrm{R}$ & $2 *(2-2)$ & $3 *(2-3)$ & $2.5 *(2-3)$ & $0(0-0)$ & $0(0-0)$ & $0(0-0)$ & $0(0-0)$ & $0(0-0)$ \\
\hline Curcumin/Sham & $0(0-0)$ & $0(0-0)$ & $0(0-0)$ & $0(0-0)$ & $0(0-0)$ & $0(0-0)$ & $0(0-0)$ & $0(0-0)$ \\
\hline Curcumin/I/R & $1 * *(1-1)$ & $2 * *(1-2)$ & $1.5 * *(1-2)$ & $0(0-0)$ & $0(0-0)$ & $0(0-0)$ & $0(0-0)$ & $0(0-0)$ \\
\hline
\end{tabular}

Tab. 4. Effects of curcumin supplementation and intestinal IR on serum IL-6 and TNF- $\alpha$ levels and intestinal MPO activity (mean \pm SD).

\begin{tabular}{|c|c|c|c|c|}
\hline & Control & IR & Curcumin/Sham & Curcumin/IR \\
\hline$\overline{\mathrm{IL}-6}(\mathrm{pg} / \mathrm{mL})$ & $349.00 \pm 165.92$ & $456.00 \pm 164.98$ & $369.21 \pm 189.99$ & $322.94 \pm 175.76$ \\
\hline $\mathrm{TNF}-\alpha(\mathrm{pg} / \mathrm{mL})$ & $154.26 \pm 6.23$ & $147.94 \pm 13.62$ & $144.05 \pm 10.82$ & $156.75 \pm 20.28$ \\
\hline MPO (ng/mg protein) & $304.53 \pm 89.42$ & $363.20 \pm 67.74$ & $253.98 \pm 52.46^{*}$ & $316.97 \pm 106.37$ \\
\hline
\end{tabular}

${ }^{*} \mathrm{p}<0.05$ compared to the IR

prevented an esophagus dysfunction induced by I/R. In this study, esophageal injury was assessed by histological method.

Oxidative stress plays an important role in mesenteric I/R injury. I/R injury leads to release of ROS or reactive nitrogen species (RNS) such as superoxide anion, hydroxyl radical, hydrogen peroxide, and peroxynitrite (20). During reperfusion, when the oxygen is re-supplied, tissue injury could be further exacerbated depending on the duration and intensity of ischemia. Meanwhile, it produces an excess of xanthene oxidase and oxygen free radicals, which would aggressively and indiscriminately damage the cellular macromolecules including DNA, proteins, and lipids (21). As it has previously been demonstrated, the development of $\mathrm{I} / \mathrm{R}$ injury is associated with different representative pathologic processes such as congestion, hemorrhage, neutrophil accumulation and lipid peroxidation (22). In this study, edema, congestion and inflammation were clearly observed in mesenteric I/R group.

Aiming to improve the survival after acute mesenteric ischemia, a number of experimental studies have been carried out in order to test several pharmacological agents that might attenuate reperfusion injury (23). Curcumin is an active ingredient of turmeric, and is a polyphenolic compound that is known for its potent antioxidant capacity (24). Several factors support the sense of studies on the effect of curcumin administration on ischemia-related disorders, namely including the fact that curcumin is a naturally occurring substance. It is non-toxic to humans, tolerated as oral doses of up to $8000 \mathrm{mg} /$ day, and evidenced safe by FDA approval (25). It was also noticed that curcumin is relatively inexpensive.

A protective effect of curcumin against hepatic I/R injury has been reported by a mechanism related to its ability for over expression of antioxidant enzymes (26). These factors together with the promising results of curcumin protective efficacy in hepatic and cardiac $\mathrm{I} / \mathrm{R}$ injury prompted us to evaluate and discover the immune-mediated mechanism of its efficacy in protection against renal I/R injury and subsequent distant organ injury. However, the protective mechanism of curcumin effect on organ ischemia/ reperfusion is not fully understood. Pre-treatment with curcumin was found to markedly attenuate the I/R-induced acute lung injury, probably through improving the oxidative stress (27). Furthermore, it has been shown that curcumin exerts a protective effect in several models of oxidant damage (28-30) including isoproterenol- induced cardiac injury (31) and I/R injury in rabbits (13). Moreover, seven days of oral curcumin supplementation $(3.6 \mathrm{~g} / \mathrm{d})$ has been shown to decrease the number of oxidative DNA adducts in malignant colorectal tissue suggesting that curcumin taken orally may reach sufficient concentrations in the gastrointestinal tract (32). In our study, curcumin pretreatment reduced the histopathologic indices such as edema, congestion and inflammatory cells caused by mesenteric I/R. Modulation of inflammatory response following $\mathrm{I} / \mathrm{R}$ injury is an important component of tissue defense, mostly because inflammation is the major component of cell death. Similarly, Karatepe et al (14) reported that curcumin pretreatment reduced the histopathologic indices of intestinal mucosal injury caused by mesenteric I/R. The investigators also reported that addition of curcumin to nutritional supplements reduced I/R injury through a mechanism suppressing the oxidative stress.

In the present study, not only did we observe a decrease in edema, congestion and inflammatory cells, we also recorded a concomitant improvement in contractile response in case of curcumin pretreatment. The findings of the present study revealed that systemic administration of curcumin improved remarkably the non-receptor-mediated (e.g. KCl-induced) and receptor-mediated (e.g. carbachol-induced) significant reduction in esophageal contractions caused by $\mathrm{I} / \mathrm{R}$ while the latter improvement even approached the sham-control levels.

Consequently, the present study is the first to show that curcumin treatment restores the reduction in esophageal smoothmuscle responses to carbachol and $\mathrm{KCl}$ in mesenteric $\mathrm{I} / \mathrm{R}$ model. Our results suggest that curcumin treatment may ameliorate the structural and functional damage observed in experimental I/R, mainly due to reducing the edema, congestion and inflammation. Nevertheless, further studies are required to understand better the exact mechanism responsible for the protective effect of curcumin.

\section{References}

1. Herbert GS, Steele SR. Acute and chronic mesenteric ischemia. Surg Clin North Am 2007; 87: 1115-1134.

2. Khanna A, Rossman JE, Fung HL et al. Intestinal and hemodynamic impairment following mesenteric ischemia/reperfusion. J Surg Res 2001;99:114-119 
465-470

3. García-Rivas GJ, Torre-Amione G. Abnormal mitochondrial function during ischemia reperfusion provides targets for pharmacological therapy. Methodist Debakey Cardiovasc J 2009; 5: 2-7.

4. Domínquez Rodríquez A, Abreu González P. Ischemia-reperfusion injury and melatonin. Rev Esp Cardiol 2009; 62: 952-953.

5. Berland T, Oldenburg WA: Acute mesenteric ischemia. Curr Gastroenterol Rep 2008; 10: 341-346.

6. Sasaki M, Joh T. Oxidative stres and ischemia-reperfusion injury in gastrointestinal tract and antioxidant, protective agents. J Clin Biochem Nutr 2007; 40: 1-12.

7. Neary P, Redmond HP. Ischaemia-reperfusion injury and the systemic inflammatory response syndrome. 123-126. In: Grace PA, Mathie RT (Eds). Ischaemia-Reperfusion Injury. London: Blackwell Science, 1999.

8. Ham M, Kaunitz JD. Gastroduodenal mucosal defence. Curr Opin Gastroenterol 2008; 24: 665-673.

9. Ganguli M, Chandra V, Kamboh MI et al. Apolipoprotein E polymorphism and Alzheimer disease: The Indo-US Cross-National Dementia Study: Arch Neurol 2000; 57: 824-830.

10. Ammon HP, Wahl MA. Pharmacology of curcuma longa. Planta Med 1991; 57: 1-7.

11. Noguchi N, Komuro E, Niki E, Willson RL. Action of curcumin as an antioxidant against lipid peroxidation. Yakagaku Zasshi 1994; 43: 1045-1051.

12. Sreejayan N, Rao MN. Free radical scavenging activity of curcuminoids. Arzneimittelforschung 1996; 42: 838-843.

13. Yeh CH, Chen TP, Wu YC et al. Inhibition of NFkappaB activation with curcumin attenuates plasma inflammatory cytokines surge and cardiomyocytic apoptosis following cardiac ischemia/reperfusion. J Surg Res 2005; 125: 109-116.

14. Karatepe $O$, Gulcicek $O B$, Ugurlucan $M$ et al. Curcumin nutrition fort he prevention of mesenteric ischemia-reperfusion injury: an experimental rodent model. Transplant Proc 2009; 41: 3611-3616.

15. Nazam Ansari M, Bhandari U, Pillai KK. Protective role of curcumin in myocardial oxidative damage induced by isoproterenol in rats. Hum Exp Toxicol 2007; 26: 933-938.

16. Bayrak O, Uz E, Bayrak $R$ et al. curcumin protects against ischemia/reperfusion injury in rat kidneys. World J Urol 2008; 26: 285-291.

17. Manikandan R, Beulaja M, Thiagarajan R et al. Ameliorative effects of curcumin against renal injuries mediated by inducible nitric oxide synthase and nuclear factor kappa B during gentamicin-induced toxicity in Wistar rats. Eur J Pharmacol 2011 (epub ahead of print).

18. Lowry OH, Rosebrough NJ, Farr AL, Randall RJ. Protein measurament with the folin phenol reagent. J Biol Chem 1951; 193: 265-275.
19. Ozacmak VH, Sayan H, Arslan SO et al. Protective effect of melatonin on contractile activity and oxidative injury induced by ischemia and reperfusion of rat ileum. Life Sci 2005; 76: 1575-1588.

20. Schoenberg MH, Beger HG. Reperfusion injury after intestinal ischemia. Crit Care Med 1993; 21: 1376-1386.

21. Mallick IH, Yang W, Winslet MC, Seifalian AM. Ischemia-reperfusion injury of the intestine and protective strategies against injury. Dig Dis Sci 2004; 49: 1359-1377.

22. Mao YF, Zheng XF, Cai JM et al. Hydrogen-rich saline reduces lung injury induced by intestinal ischemia/reperfusion in rats. Biochem Biophys Res Commun 2009; 381: 602-605.

23. Poussios D, Andreadou I, Papalois A et al. Protective effect of a novel antioxidant non-steroidal anti-inflammatory agent (compound IA) on intestinal viability after acute mesenteric ischemia and reperfusion. Eur J Pharmacol 2003; 465: 275-280.

24. Toda S, Miyase T, Arichi $\mathbf{H}$ et al. Natural antioxidants. III. Antioxidative components isolated from rhizome of Curcuma Longa L. Chem Pharm Bull (Tokyo) 1985; 33: 1725-1728.

25. Cheng Al, Hsu CH, Lin JK et al. Phase I clinical trial of curcumin, a chemopreventive agent, in patients with high-risk or pre-malignant lesions. Anticancer Res 2001; 21: 2895-2900.

26. Shen SQ, Zhang Y, Xiang JJ, Xiong CL. Protective effect of curcumin against liver warm ischemia/reperfusion injury in rat model is associated with regulation of heat shock protein and antioxidant enzymes. World J Gastroenterol 2007; 13: 1953-1961.

27. Sun J, Yang D, Li S et al. effects of curcumin or dexamethasone on lung ischemia-reperfusion injury in rats. Eur Respir J 2009; 33: 398-404.

28. Mythri RB, Jagatha B, Pradhan N, Andersen J, Bharath MM. Mitochondrial complex I inhibition in Parkinson's disease: how can curcumin protect mitochondria? Antioxid Redox Signal 2007; 9: 399-408.

29. Wei QY, Chen WF, Zhou B, Yang L, Liu ZL. Inhibition of lipid peroxidation and protein oxidation in rat liver mitochondria by curcumin and its analogues. Biochim Biophys Acta 2006; 1760 (1): 70-77.

30. Rastogi M, Ojha RP, Rajamanickam GV et al. Curcuminoids modulates oxidative damage and mitochondrial dysfunction in diabetic rat brain. Free Radic Res 2008; 42: 999-1005.

31. Nazam Ansari M, Bhandari U, Pillai KK. Protective role of curcumin in myocardial oxidative damage induced isoprotenol in rats. Hum exp Toxicol 2007; 26: 933-938.

32. Ghoneim AI, Abdel-Naim AB, Khalifa AE, El-Denshary ES. Protective effects of curcumin against ischemia/reperfusion insult in rat forebrain. Pharmacol Res 2002; 46: 273-279.

Received October 17, 2011. Accepted October 30, 2011. 